\title{
El frustrado accionar de un partido socialista nacional en la Argentina (1915-1922)
}

\author{
Carlos Miguel Herrera
}

Université de Cergy-Pontoise - CPJP

Carlos.Herrera@u-cergy.fr

Title: The unfulfilled life of a socialist party national in Argentina (1915-1922)

Resumen: Este trabajo se propone la primera reconstrucción de conjunto del accionar del Partido Socialista Argentino, formado en torno a Alfredo Palacios, tras su salida del socialismo oficial. En algo más de un lustro de vida, el nuevo partido intentó desarrollar un discurso nacional como fundamento del cambio social. Su incapacidad para forjar una identidad diferente del viejo socialismo, y sus sucesivos fracasos electorales, lo llevaron a un rápido final.

Palabras clave: Partido Socialista - Alfredo L. Palacios - discurso nacional identidad política

Abstract: The article offers the first overall reconstruction of the "Argentine" Socialist Party, organized around Alfredo Palacios after his departure from the "official" socialism in 1915. In more than five years of life, the new party tried to develop a national discourse as the foundation of social change. His inability to forge a sharp different identity from the old socialism, and his successive electoral failures, led it to a quick end.

Keywords: Socialist Party - Alfredo L. Palacios - national discourse - political identity

Recepción: 6 de marzo de 2018. Aprobación: 30 de abril de 2018 .

(Archivos, año VII, $\mathrm{n}^{\circ}$ 13, septiembre de 2018, pp. 121-141) 
El Partido Socialista Argentino (de aquí en más PS-A) surgió tras la separación de Alfredo Palacios del Partido Socialista (PS), en junio de 1915. Su salida había creado una gran excitación en torno a su persona, ya convertido en la figura pública más importante de la izquierda. Así, en el gran banquete que organizan los cronistas parlamentarios para tributarle un homenaje tras renunciar a su banca, y donde se dan cita variadas figuras de la vida cultural argentina, Alberto Gerchunoff lanza su candidatura politica, en el marco de un fuerte rechazo al viejo PS, hecho aún más explícito por otro de los contertulios de esa noche, Ricardo Rojas, que se preguntaba: “¿Cómo cifrar nuestra esperanza de regeneración nacional ni de redención popular, en eso que para escarnio de las clases obreras y de la democracia argentina sigue llamándose "el partido socialista argentino"?” (AA.VV., 1915: 99).

A principios de septiembre de ese año, un grupo de militantes socialistas cercanos a Palacios (como A. Torcelli y J. Muzilli) o críticos de la dirección (como M. Casaretto), pero en ausencia del antiguo diputado, se reúne en un congreso en Buenos Aires para crear una nueva organización, que contará con el aditamento de "Argentino". Palacios termina adhiriendo al PS-A en una carta fechada una semana más tarde, donde saluda la orientación nacional de la nueva "Declaración de principios".

Profesando un sano nacionalismo, nos sentiremos vinculados a la tierra en que hemos sufrido y hemos amado, y conceptuaremos la patria como obra de civilización, como fuerza de solidaridad que está por encima de todos nuestros egoísmos, $\mathrm{y}$ que tiene como fundamentos la justicia y la libertad.

En otro lugar analizamos cómo se planteaba esa identidad "nacional" dentro de una cultura socialista ya consolidada (Herrera, 2018), lo que explica, a la postre, su carácter demasiado inestable para configurar un nuevo socialismo, como ya se puede observar en la gran crisis interna que sacudirá al nuevo partido al año de su nacimiento. Pero esa primera particularidad conducía a dar al socialismo un acento reformista más marcado, un carácter "práctico", que llevaba a situar al derecho como su medio específico. A obtener una banca parlamentaria apuntarán sus mayores esfuerzos, sobre todo a partir de 1917. Su fracaso repetido en este plano apresurará el final del promisorio partido, que desaparece hacia 1922. Nos proponemos reconstruir aquí la historia del PS-A a partir de su actuación pública.

\section{Un nuevo partido para otro socialismo}

El PS, por intermedio de su Comité Ejecutivo, juzgaba que Palacios 
se había separado "voluntariamente" de sus filas, tras aceptar un nuevo duelo, con el diputado radical Horacio Oyhanarte. La prohibición de esa práctica, tenida por burguesa, bárbara y anacrónica, había sido objeto de algunas idas y vueltas en las instancias partidarias: tras dejar sin efecto la cláusula del art. 48 del estatuto en el XII Congreso Nacional, de mayo de 1914, en tanto actividad privada, había sido restituida por el voto general poco después, aunque se discutía la legitimidad de su aprobación o la legalidad de su incorporación a la normativa partidaria por esta vía.

La decisión del II Congreso extraordinario del PS, en julio de 1915, de rechazar la apelación interpuesta por Palacios a la medida del CEN, había conducido a un grupo de sus militantes ${ }^{1}$ a reunir un Congreso de "agrupaciones socialistas disidentes" el 4 y 5 de septiembre de 1915, que aprobó un nuevo "Programa mínimo", antecedido de una también novedosa "Declaración de principios", y completando su tarea fundacional dotando de estatutos a la nueva fuerza.

Se reivindicaban alli los cambios que había producido en la política argentina la llegada del socialismo, su programa de realizaciones y la eficacia de sus métodos, que habian llevado a los triunfos electorales capitalinos, con cerca de 40.000 votos, un trasfondo sin duda determinante en la decisión de lanzarse a la construcción de una nueva fuerza política. Ese caudal mostraba que no eran sólo trabajadores quienes apoyaban la acción socialista, sino también "los elementos liberales, la pequeña burguesia", e incluso "la minoria ilustrada de la clase dirigente". Esto habría implicado, como se anota con lucidez en el documento fundacional, el deber de "ajustar sus actos a las características del ambiente", manteniendo "en su organización el espíritu democrático que, como una fuerza cardinal, ha orientado a nuestro pueblo desde sus oscuros orígenes", y, sobre todo, que el triunfo se traducía en una más amplia acción parlamentaria. Pero he aquí que el PS, "desencarnado de la tierra donde pretendia arraigar", habia perdido su rumbo, cayendo, paradójicamente, en las prácticas de la política criolla, ya no solo del dogmatismo y el sectarismo.

De esa crisis nacía el nuevo PS-A, "un retoño destinado a prender en las entrañas de la nacionalidad". Se debía pues realizar el ideal socialista "dentro de las modalidades inherentes a nuestra democracia", lo que alentaba una orientación más abiertamente reformista, e incluso de colaboración. Así retraducidos los conceptos, la lucha de clases solo tenía sentido como "lucha concreta contra los privilegios" o "en fórmula

1. Los delegados que habian apoyado a Palacios en el Congreso del PS habían sufrido el hostigamiento de la barra y encontraremos muchos de ellos en el nuevo partido (Casaretto, A. Mantecón, Othaz, Lapido, Rosáenz, Ghio, Castro Zinny, Melópulos). 
práctica que dé a los trabajadores la clave de su organización", mientras que "la conquista de los poderes públicos" era resignificada como "acción directa o electoral", para "intervenir en la sanción o ejecución de las leyes". Las desigualdades sociales y económicas se achacan menos al "exclusivismo de clase" que a "las supervivencias anacrónicas", a "las instituciones vetustas", a las "tradiciones heredadas". El ataque a las formas, más que a los hombres, daria, aseguraba el "Manifiesto", un carácter menos hostil a la lucha.

Si la apropiación de los medios de producción generaba una organización social injusta, en el caso argentino era la propiedad privada de la tierra la que había "facilitado" el "trasplante y la aplicación del régimen capitalista europeo". En consonancia con ello su "Declaración de principios" sostenía que la libertad económica, la primera de las libertades, sólo sería posible cuando los trabajadores poseyeran los medios de producción. La organización del proletariado era la "condición indispensable" para la transformación y el texto desarrollaba una serie de instrumentos que no aportaban novedad con respecto al viejo tronco: la "difusión de la doctrina del socialismo científico", la acción gremial con "inteligencia", para capacitar a la clase obrera para la obtención de mejoras inmediatas para elevar su nivel de vida, la acción cooperativa, para prepararse a la administración de los bienes comunes, y la acción política, para la conquista de los poderes públicos.

El perfil se recortaba más neto en los estatutos de la nueva fuerza, más cortos, simples y funcionales que los del PS. Por cierto, la organización territorial era la base, retomando los centros y las federaciones. En cambio, las agrupaciones no recibian un tratamiento particular como en la antigua norma (ni siquiera se preveía la constitución de una agrupación femenina, contrariamente a la vieja práctica). El Comité ejecutivo desaparecía también, ocupando su lugar un Consejo nacional, de 20 miembros, que representaban cada uno una vigésima fracción de los afiliados, siendo responsables ante la federación que los acreditaba, por un mandato de 2 años. Se preveía el nombramiento, en su seno, de una Junta ejecutiva; pero no integraban el Consejo nacional el director del órgano partidario ni los legisladores, como tampoco los asalariados del partido. Por otro lado, sus miembros no tenían voto en el Congreso, pero elegían por mayoría absoluta el director del órgano partidario. El Congreso se reuniria, como en la antigua norma, cada dos años, retomándose igualmente la institución del voto general. En el capítulo consagrado a la disciplina, mucho menos detallado que el del PS, se afirmaba que los estatutos "garantizan a los afiliados la más absoluta libertad de opinión con respecto a la organización interna del partido", y las críticas que se hicieran a su dirección no podían ser nunca causal de exclusión. 
Ante las sospechas, que no faltarán, de que se construía una fuerza en torno a un hombre, el PS-A reivindica su "impersonalismo"; incluso su órgano de prensa adoptará en sus avisos el subtítulo "órgano impersonal", aunque esto daba cuenta también de tensiones internas. Acompañan a Palacios un conjunto de afiliados del viejo partido, como M. Casaretto, A.J. y C. Torcelli, V. Rosáenz, J.F. y A. Mantecón, E. Othaz, M. Lapido, E. Melópulos, F. Ghio, Á. González, Carolina y J. Muzilli, C.N. Caminos, N. Strático, V. French Matheu, M. Daumas, aunque otros, como D. Castro Zinny o E. Miranda Gallino, eran adherentes recientes. Pero se sumaban además otros hombres que no provenían de la tradición partidaria, pero eran amigos de Palacios, como S. de Madrid, J. Quesada, J.A. Saldias, H.P. Holmberg, R. Paz, N. Mercader o J. Erikson.

Esta apertura se veía reflejada en las páginas del periódico partidario, donde aparecian como colaboradores especialistas que no militaban necesariamente en la fuerza. Llegado el caso, se podian publicar viejas páginas de José Ingenieros. En algunas, ocasiones, por ejemplo para la velada organizada el $1^{\circ}$ de mayo de 1916 en el Teatro Victoria, se contaba con el concurso de Almafuerte o de Alfonsina Storni.

El primer Secretario general de la nueva organización era V. Baliño, pero una vez organizada la Junta ejecutiva nacional pasaba a ocupar el cargo un experimentado Casaretto, integrando la mesa R. Arata, Ghio, González y Lapido (que desempeñará luego provisoriamente la Secretaría general), y en las comisiones, entre otros, encontramos a J. Mantecón, J. Muzilli, Rosáenz, Vidal, Caminos, etc. Como se ve Palacios no participaba directamente de los órganos de dirección partidaria-ocupada mayormente por los fogueados ex militantes del socialismo- conservando esa distancia de amplios sentidos.

El tipo de organización replicaba la del viejo PS, aunque en una versión simplificada que se quería menos estricta y formal -la sencillez de la carta orgánica se reivindicaba siempre como un rasgo propio del nuevo socialismo, aunque más tarde se llamará a la disciplina y a darse reglas-. Para ser reconocidos, los Centros debían contar con 20 miembros como minimo en la ciudad de Buenos Aires (la mitad en los otros distritos). Su funcionamiento interno incluía la reunión mensual en Asamblea, una comisión administrativa a su frente y la organización de una biblioteca. El partido se organizaba rápidamente en toda la Capital, con locales en 16 circunscripciones (a veces más de uno en ellas), en la Provincia de Buenos Aires (incluyendo localidades como Bahía Blanca, Bragado, Campana, Olavarria, 9 de julio), Santa Fe (Rosario), Córdoba (pero en el interior) y Entre Ríos (Concordia). ${ }^{2} \mathrm{Al}$ mismo tiempo, en otro

2. En algunos de estos lugares, según informa el órgano partidario, nacen periódicos locales como Democracia Social de Campana o El Nivel de Río Cuarto. 
alarde de organización más abierta, existian en algunas secciones de la Capital Federal (la $4^{\mathrm{a}}$, la $9^{\mathrm{a}}$ ) centros independientes que "secundan la acción del Partido", o al menos la persona de Palacios. ${ }^{3}$ Durante la celebración del $1^{\circ}$ de mayo de 1916 se dejará constancia de actos en varias ciudades bonaerenses aparte de La Plata (Campana, Juárez, Pergamino, Olavarría, General Lamadrid).

Desde noviembre de 1915, la fuerza contaba con su órgano oficial, La Acción, dirigido por A. Torcelli, ligado a Palacios de larga data. ${ }^{4} \mathrm{Su}$ proclamada ambición de transformarse en diario nunca se materializará, y conservará una existencia semanal hasta junio de 1916, cuando los confesados problemas de tesorería lo llevan a una aparición más irregular. El periódico no cuenta, como se precisa para información de los militantes, con personal asalariado, lo que facilitaba la contribución de "colaboradores". Esto iba de algún modo en consonancia con el hecho de que las candidaturas electorales del socialismo argentino mostrarán un apoyo más amplio concitado por la figura de Palacios. Pero la publicación expresará cada vez más la posición del sector más ligado a las tradiciones socialistas. ${ }^{5}$

Uno de los lemas del PS-A era "sembrar ideas y cosechar sanas consciencias" y las notas de su órgano se dirigen a un público culto. De hecho, la "juventud estudiosa" era una de las cibles del nuevo partido -la crónica periodística reconocerá uno de los sectores sociales más numerosos del PS-A, dado el predicamento de Palacios, ya por entonces profesor universitario-. El periódico cuenta incluso con una sección de divulgación científica que se repite número tras número, mostrándose siempre atento a los problemas educativos, ya sea con artículos sobre el método Montessori o sobre los niños con retraso. Pero la actividad deportiva no era descuidada tampoco, y su cobertura en la materia era siempre importante, dando la tabla de posiciones del campeonato de futbol, y noticias sobre ciclismo, motociclismo, automovilismo y deportes náuticos. Incluso se conforma un team del PS-A, con el nombre

3. Por cierto, las candidaturas de Palacios serán siempre respaldadas por comités independientes, y la práctica se repite en la primera elección de 1916. Más tarde, en la elección legislativa de 1918, por ejemplo, encontramos un "Comité de ciudadanos independientes", un "Comité de estudiantes pro-ruptura de relaciones con Alemania", el "Centro obrero pro-aliados", etc. Y aún en las elecciones nacionales de 1920 se habla de un "Comité de estudiantes".

4. Cuando luego de algunas vicisitudes, Palacios se afilia al PS, en septiembre de 1901, lo hace en el centro de La Plata, que dirigían los hermanos Torcelli (Dickmann 1917: 122-123).

5. A partir de septiembre de 1916 su dirección entra en conflicto cada vez más marcada con Palacios y Mantecón. Tras cambiar de formato en diciembre de 1916, sus rastros se pierden hacia marzo de 1917. 
"La Acción socialista argentina", que juega en Tercera división. La mira política, sin embargo, no desaparecía: se muestra en general crítico de la Asociación Argentina de Futbol, y aunque defiende el box, rechaza su profesionalización.

Un signo del interés con que era observado el nacimiento del partido en otras esferas que las tradicionalmente ligadas al socialismo era la gran cantidad de anuncios agrupados de bancos (de la Nación, Español del Río de la Plata, Nuevo Banco Italiano, de Londres y Brasil, Municipal de Préstamos y Alemán Trasatlántico) con que contaba el periódico, sobre todo en sus primeros meses de vida. De manera general, la publicidad era abundante en sus páginas, tanto de trajes e indumentaria de ciudad, incluyendo a la tienda Gath y Chávez, como de cigarrillos "43", o aún de la cerveza Quilmes y hasta la yerba paraguaya Palacios, y en el mismo rubro de diversión, los recreos. Tampoco falta la réclame de la emblemática colección "La Cultura argentina" que dirigia Ingenieros para la casa Vaccaro.

Las disquisiciones del PS-A, como vimos en el documento fundacional, daban cuenta de la importancia que se le otorgaba al problema electoral como medio de acción política. Pero, al mismo tiempo, parecía centrada en torno a la persona de Palacios, y en la Ciudad de Buenos Aires, donde el socialismo había logrado importantes triunfos tras la reforma de 1912. Así, la elección presidencial de 1916 era vista como una disputa entre UCR y PDP, y cuando se producen las elecciones, los "Argentinos" no presentan candidatura al Ejecutivo.

Ante las acusaciones que provenían del viejo PS, los nuevos socialistas se desentendian de todo "electoralismo", afirmando que la tarea orgánica de la fuerza era la educación del pueblo. Empero, apenas constituidos, los "Argentinos" se presentaron a las elecciones municipales de Avellaneda, en noviembre de 1915, con una lista encabezada por Casaretto, proclamando que el municipio era la base de la democracia. Según la crónica partidaria, los actos de campaña llegaron a reunir 4.000 personas, lo que quizá sea exagerado. Producido el comicio, se denunciará el fraude cometido, aunque se reconocía que la cantidad de votos obtenidos (cerca de 500), no bastaban para la concejalía. Sin embargo, se valoraba que en 8 mesas (sobre 29) habian obtenido más votos que el PS...

La actividad propagandística del novel partido se tornará muy importante de cara a las elecciones del 2 de abril de 1916, llegándose a contabilizar 40 conferencias semanales en la Capital. ${ }^{6}$ Los actos tenian en general a Palacios como principal orador, y eran seguidos en algunas ocasiones, siempre según el periódico, por más de 8.000 personas. La

6. La Acción, $\mathrm{n}^{\circ}$ 17, 1 de marzo de 1916. 
confianza en alcanzar la victoria ante "el socialismo dogmático y negativo" parecía primar ampliamente. Por cierto, se denunciaba desde La Acción la constante perturbación de sus reuniones llevadas a cabo por simpatizantes del PS, a veces al grito de “¡Palacios no/Justo si!"...7

El PS, por su parte, afirmaba desde las columnas de La Vanguardia que los periódicos nacionales, y en particular La Razón, apoyaban al nuevo grupo. En todo caso, en las páginas del vespertino encontramos algunos reportajes de cara a los comicios, no sólo a su principal figura pública, sino también a Torcelli e incluso a Rosáenz, al que se señala como el único obrero manual candidato a la diputación. La nota realza no sólo su oficio de carpintero sino también su largo cursus honorum en el viejo PS, al que había ingresado en mayo de 1894. De hecho, en sus respuestas, se encuentran reafirmadas las viejas propuestas del socialismo, como un "librecambismo convencido", el fin de los impuestos aduaneros que encarecen el consumo de los trabajadores, y aunque defendia la industrialización, rechazaba toda protección del Estado, en particular del vino y el azúcar. Su candidatura promovía además la derogación de las leyes de Residencia (4.144) y Defensa social (7.029).

El fracaso de la candidatura de Palacios, pese a haber alcanzado más de 33.000 votos (y un promedio de 8.500 votos para los otros candidatos) ${ }^{8}$ representó un primer golpe, y pronto aparecerían los síntomas de una crisis, que posiblemente se incubaba desde el nacimiento del PS-A.

\section{La división interna}

El conflicto toma estado público cuando se preparaba una fiesta para celebrar el primer aniversario de la fuerza, anunciándose como oradores en el salón Augusteo a sus principales figuras, Palacios, Casaretto y Torcelli. Pero finalmente el líder no se hace presente, y sólo los dos últi-

7. Particularmente graves parecen haber sido los incidentes producidos durante la proclamación de candidatos del PS-A en el Teatro Argentino de La Plata, multiplicándose las acusaciones cruzadas en la prensa. La hostilidad no se detiene con la campaña electoral: también se denunciarán los gritos y silbatinas al pasar ante la sede del Partido, en Córdoba 1150, durante la manifestación del $1^{\circ}$ de mayo de 1916. 8. La Argentina, 15 de abril de 1916. Los votos de Palacios eran similares a los alcanzados en 1912 bajo la etiqueta socialista (32.000) pero esta vez no alcanzaban para una banca. Y se podía observar ya un elemento que daba cuenta de la amplitud de sus apoyos: había cosechado sus mayores votos en secciones del Norte porteño, como la $18^{\mathrm{a}}$ y la $19^{\mathrm{a}}$. La lista del PS-A estaba integrada, además, por A. Mantecón, de Madrid, A. Torcelli, Lapido, Castro Zinny, Paz y Rosáenz. En la Provincia de Buenos Aires, el otro distrito donde se presentan, la boleta era encabezada por Casaretto, Caminos y Á. Gismondi, pero los nombres se repiten en las candidaturas legislativas provinciales (y sólo en las secciones $1^{\mathrm{a}}, 2^{\mathrm{a}}, 4^{\mathrm{a}}$ y $6^{\mathrm{a}}$ ). 
mos toman la palabra junto a Rosáenz, Miranda y Antola. Era el primer signo de la crisis que pronto iba a estallar en el PS-A. Por lo pronto, se podía notar que en la celebración no se cantó, según informaba el periódico oficial, el himno nacional, aunque sí "La Internacional", "Hijo del pueblo" y el "Himno de los trabajadores". Con todo, primaba en los oradores el optimismo en su voluntad de crear "una nueva fuerza política representativa de la clase trabajadora". Ciertamente, Casaretto estimaba que los partidos, pero también los propios trabajadores, no se habian preocupado por las grandes reformas económicas, que beneficiaran al pueblo todo, prefiriendo concentrarse en reformas gremiales de carácter sectorial. Por cierto, se podía leer también en tono de advertencia que "la sedimentación del socialismo en el alma de los hombres reclama sacrificios, amontona disgustos, impone penurias". ${ }^{9}$

A decir verdad, las polémicas en el PS-A se habian tornado recurrentes ya antes y tocaban, como podía preverse, la extensión del nacionalismo en el nuevo ideario. Así, "Pitágoras" firmaba un suelto en el $\mathrm{n}^{\circ} 26$ donde fustigaba a quienes pensaban que la separación con el PS pasaba por el amor por la bandera azul y blanca, que significaria caer en la idolatría de los símbolos. Las causas de la secesión eran más bien la ausencia de ideales, la falta de libertad, como así también la ausencia de rectitud y pureza en los procedimientos internos, sujetos a "las caprichosas imposiciones de la nepótica oligarquía reinante". Por eso un nuevo partido debía hacer obra práctica, educar al pueblo desarrollando la conciencia de clase, fundando cooperativas y agrupaciones sindicales y "sobre todo, ajustando nuestros actos públicos y privados a nuestras prédicas".

Las tensiones entre antiguos militantes socialistas y nuevos miembros del PS-A se expresaba en intercambios de cartas, por ejemplo entre un tal "Ángel Sesfies" (que revelará ser el seudónimo masculino de Carolina Muzilli) y De Madrid, destacado profesor de medicina, donde "el primero" reivindicaba sus 10 años de militancia contra los 5 meses del candidato a diputado, para afirmar luego que la creación del PS-A no era un "gesto" para rodear un candidato sino la continuación de viejos ideales, a lo que De Madrid respondía acusando a su contrincante de ser un "politicastro a la usanza del viejo partido"... Pero se trataba ante todo de cuestiones de fondo: Muzilli le achacaba a su camarada negar la lucha de clases, sin la cual no se podía ser socialista, a la par que su personalismo. O aún la creencia de que un socialismo argentino sería diferente al europeo, por el hecho de que aquí sería más fácil ser propietario. ${ }^{10}$

9. La Acción, $\mathrm{n}^{\circ}$ 36, 2 de septiembre de 1916.

10. A Muzilli le responde la señorita Mercedes de Madrid, hija del médico y estudiante secundaria, que pone en tela de juicio que Carolina sea la autora de la réplica prefi- 
Pero a fines de septiembre las columnas del diario daban cuenta ya de una crisis de mayores proporciones. Esta tocaba a las seccionales capitalinas que, según las autoridades nacionales del partido, no habían elegido a sus delegados a la Federación local por mayoría absoluta, sumado a otras irregularidades. La mayoría de los delegados capitalinos, en lugar de aceptar el requisitorio, deciden desconocer al Consejo Nacional, asumiendo la dirección del partido en la Capital. Y los implicados son... Palacios junto a J. Mantecón y R. Paz, que deciden constituir un nuevo Consejo Nacional.

El sector orientado por Casaretto denunciaba que Palacios siempre habia querido permanecer fuera de la fuerza, sin afiliarse, por fidelidad a otro centro integrado por ex integrantes del Partido Nacionalista, sumándose a la contestación interna los socialistas interesados por el caudal electoral de su figura. Condenaba además el boicot que se estaba llevando a cabo a La Acción desde ese sector (desde unas semanas antes los anuncios profesionales se habian reducido, incluido el del estudio de Palacios). Y se atacará la usurpación del nombre del PS-A por el periódico Nueva Era de Mantecón. Por cierto, en la disputa al interior del "Argentino" no se pierde de vista el viejo enfrentamiento con el PS, y se afirma desde el órgano oficial que las acusaciones de ser "lacayos de Palacios" no tenian sentido, visto que se lo separaba por no respetar los estatutos.

La Acción juzgaba que Palacios sólo quería formar un "grupo electoral", según el modelo europeo de partido radical, atrayendo a liberales, nacionalistas y radicales progresistas, pero con el título de socialistas. El sector "oficial" creía conservar la mayoría de los Centros de la Capital -donde reivindica al 60\% de los afiliados-y la Provincia, una prueba de organicidad por fuera de "dioses tutelares" e "imposiciones caudillistas". Pero en octubre se denuncia la usurpación del local central por los disidentes, comparando su accionar con "las patotas del Centenario".

Pese al conflicto abierto, el grupo de Casaretto participa en las elecciones municipales de Avellaneda, La Plata y Juárez de noviembre de 1916, y el periódico continúa saliendo sin cambiar su fisionomía, incluida su acendrada tonalidad jurídica, y conservando publicidad (se insiste que era el mejor periódico obrero para la publicidad comercial...).

Con Casaretto y Torcelli, se alistaban Rosáenz, Antola, Daumas, Strático, Ghio, Ramón Vidal y González, mientras que acompañaban a Palacios, calificado de "usurpador", aparte de los hermanos Mantecón (Juan aparece como el nuevo secretario general del PS-A), Paz, De Madrid, Lapido, Miranda Gallino y Castro Zinny (más tarde, Antola se une 
a ellos). Pero como era de prever, es en torno al carismático líder que se reconstituye prontamente la fuerza. En efecto, la organización no tiene suficiente autonomía programática por fuera del líder.

En verdad, se puede ver en esta crisis un intento de ampliar las bases de un nuevo partido, menos socialista que progresista, mientras que quedaba más claro que el otro grupo se había distanciado del PS más por sus prácticas nepotistas que por el programa. Por eso se acusa ahora al sector palacista de "patrioterismo", e incluso aparece un tinte de clase, cuando se denuncia a esos abogados, esos doctores, esos ingenieros, por haber querido vestir hábitos socialistas, aunque no dudaban en atropellar un local donde se reúnen insignificantes obreros. ${ }^{11}$ La crítica, claro está, se extiende una vez más al PS oficial, recordando que "el verdadero socialismo está en pugna con todas las clases imperantes".

La Vanguardia dedicaba un suelto satírico al conflicto, bajo el título "Un concurso dramático-amarillo", comparando al PS-A con una bolsa de gatos, con Palacios por un lado, llamando a sus acólitos los "mosqueteros", y Torcelli, como jefe de los "revolucionarios", por el otro, hablando de un sainete. Pero la crisis partidaria marcaba una refundación de los objetivos de la fuerza, cada vez más centrados en la lucha electoral.

\section{Un partido palacista}

El grupo de Palacios organizaba su propio congreso -denominado Primero Extraordinario- en la ciudad de Buenos Aires, del 8 al 10 de diciembre de 1916, y sus delegados parecen provenir sólo de la Capital Federal -eran cerca de 40, según los diarios, y tanto obreros como miembros de profesiones liberales descollaban por su juventud-. Desde un proscenio decorado por las banderas argentina y roja, y los retratos de Rivadavia y Jaurès, su primera declaración pública era una condena del "crimen de la guerra" que seguía asolando Europa. La ansiada paz, según el documento, se asentará entre otros elementos en la "afirmación de las nacionalidades", reafirmando lo que denomina su "pensamiento fundamental de partido" bajo la forma de un slogan: "la redención para los pueblos, los pueblos para las patrias, las patrias para la humanidad".

Justamente, en el marco del conflicto interno, el congreso decide puntualizar que, "si bien la lucha en que el partido está empeñado en pro de los trabajadores no excluye la conveniencia de la acción nacionalista", "ningún socialista argentino" debía pensar que el ideal internacionalista había caducado en todo lo que tocaba al proletariado. En ese sentido, se reafirmaba que el nacionalismo "compatible con los principios y programas del partido" excluía "el culto incondicional de los símbolos

11. La Acción, n 43, noviembre de 1916. 
y tradiciones de la patriotería burguesa", y tampoco era "retroactivo y solidario" con el practicado por las otras fuerzas políticas. Antes bien, "se cifra en el logro de una mayor cultura general, en el afianzamiento de la libertad, y en la institución del respeto a los derechos de los trabajadores que producen la grandeza de la nación". También se aprobaban sendos pronunciamientos contra la deportación de obreros belgas y en apoyo a la huelga de los trabajadores del puerto. En la clausura, se censuraba la carestía de vida, pidiendo una vez más la supresión de los impuestos que gravaban el consumo, y reclamando medidas en favor de los consumidores y contra los trusts e intermediarios. Otro tanto se hacía, para que no quedasen dudas sobre su perfil, con respecto a la situación de los trabajadores en los obrajes del interior, denunciando condiciones atentatorias a los principios de la humanidad. Al mismo tiempo se reclamaba una ley para la conformación electiva de la municipalidad porteña y la derogación de las citadas leyes 4.144 y 7.029. Si se repetían los homenajes tributados a la memoria de Rivadavia, Sarmiento, Alberdi, Echeverría y Jaurès, la crónica periodística deja constancia también de los votos de simpatía por figuras del socialismo europeo.

El congreso encaraba además una reforma estatutaria, cuya medida más importante reducía el Consejo nacional a 10 miembros, elegidos por el voto general, mientras que la instancia dirigente de la Federación de la Capital, a la que parecía reducirse el PS-A, se conformaba con un miembro por cada Centro - se declaraba contar con 23 centros seccionales-. Pero su propósito interno quedaba manifiesto con la expulsión de los afiliados que conformaban el otro sector, ${ }^{12}$ aduciéndose como causal los procedimientos llevados a cabo para "impedir la libre expresión de los oradores socialistas argentinos", amén de la extralimitación de sus funciones en la constitución de la federación metropolitana. Por cierto, se desconocia de antemano el congreso que preparaba el otro sector en unas semanas.

Su declaración final ratificaba el programa dado en el Congreso constituyente y:

Consecuente con este programa de acción, repudiando el carácter dogmático de la doctrina y las disciplinas partidarias aplastantes, será un factor importante de nuestra democracia proclamando un elevado nacionalismo, que lo orientará siempre en la lucha por la emancipación de los trabajadores y la grandeza de la patria.

12. Aparte de Rosáenz, Casaretto y Torcelli, integraban la nómina Ghio, Daumas, Strático, Vidal, Marcelino Rodríguez, Arata, C. Casetta, J. Fernández Presa, entre otros, es decir aquellos que provenían del histórico PS y tenían como base de actuación la Provincia de Buenos Aires. 
El PS-A retomaba rápidamente la acción propagandística con conferencias y actos callejeros, y los diarios informan también de diversas incidencias de su vida interna que iban en el sentido de una normalización.

Entre tanto, el 23 y 24 de diciembre, el otro grupo organiza en La Plata su propio Primer Congreso Extraordinario. Alli se aseguraba que el nombre de "Argentino" no era esencial al proyecto, porque lo que se buscaba era escapar a un régimen interno antidemocrático de funcionamiento. En ese sentido, se ratificaba que había un solo modo de practicar el socialismo: "el que enseña a los trabajadores a agremiarse, a fundar cooperativas y a intervenir en la politica”. En su informe se denunciaba el conflicto interno en términos de organización, poniendo en tela de juicio la existencia de comités electorales "de marcada inclinación personal”. La declaración final, que insistía en reafirmar el ideal internacionalista del socialismo, se declaraba contra la guerra y denunciaba el patrioterismo.

Pero los medios de prensa nacional, desde entonces, sólo reconocerán al sector de Palacios como PS-A, y el otro grupo se perderá en el tiempo (ni siquiera se había informado en la prensa nacional la tenida de su congreso en La Plata). Aun así, el grupo de antiguos socialistas continuará publicando La Acción durante los primeros meses de 1917, y aunque la guía profesional enflaquece, la publicidad comercial no disminuye. Pronto se informa, sin embargo, de "la completa falta de recursos", asi como las dificultades de toda indole, y un bono de empréstito interno es lanzado a favor del periódico pero los números terminan espaciándose. Con todo, se puede recalcar en sus páginas una reafirmación del socialismo en sus extremos más radicales, definido como "la socialización de los medios de producción y de cambio y la transformación de la sociedad capitalista en sociedad colectivista". Y para marcar diferencias, se publican textos de Marx, al que se le da estatuto de "maestro". Asimismo, se llama más enérgicamente a la acción, en particular en el campo sindical. De hecho, se admitía que los oradores de la pasada campaña electoral no siempre explicaron con claridad "los propósitos y principios netamente socialistas", aunque se hacia hincapié en la prédica que la publicación siempre hizo a los trabajadores para el estudio y la organización gremial. Los ataques se focalizaban en los "caballeros asaltantes de locales ajenos", denostando su nacionalismo, por ejemplo en una conferencia de Castro Zinny que denuncia como una apología del gobierno radical, hasta calificarlos de "traidores del proletariado". Se llegaba incluso a defender al PS de las críticas nacionalistas, porque, aunque no realizaran su deber, estaban por encima de los representantes radicales o conservadores. Pero tampoco se olvidan las antiguas querellas con el grupo oficial, transformando la disputa a tres bandas, remontándose con nuevos detalles la historia de 
los conflictos al año 1913. Al mismo tiempo, este sector había iniciado acciones judiciales para recuperar el local de la calle Córdoba. Pero las discordias internas también atraviesan al grupo y en marzo de 1917 el diario parece por última vez.

El remozado PS-A, siempre con Mantecón como secretario general, tendrá su II Congreso nacional ordinario en enero de 1918. La prensa que cubre el evento da cuenta de un estrado adornado una vez más por los pabellones argentinos y rojos, y los ya habituales retratos de Rivadavia y Jaurès -la crónica periodística agrega que en el palco del local de la Sociedad XX de Septiembre "habia algunas damas"-. Palacios es acompañado en el Consejo Nacional por Miranda Gallino y el nombrado Mantecón, entre los fundadores, y R. Garbellini, F. Cerminaro, L. Moyano entre los nombres más recientes, mientras que siguen perteneciendo a la fuerza De Madrid, Saldias, French, Matheu y A. Mantecón, que preside la citada reunión. El cónclave dejaba adivinar que se trataba ante todo de un partido metropolitano, aunque se dejaba constancia de representación en las provincias de Buenos Aires y Tucumán, con un total de 20 centros declarados. Sus deliberaciones aprobaban sendos pronunciamientos para reclamar, una vez más, la reglamentación de las elecciones municipales de la Capital Federal, a la par que se denunciaba la represión contra los sindicatos, que busca "destruir la organización obrera y el uso legítimo del derecho de huelga".

En un nuevo "Manifiesto al pueblo de la Capital" que clausuró sus trabajos, se ratificaba que con su nacimiento buscaba terminar con los extravios del viejo PS, construyendo una agrupación que se "adaptara a las modalidades de nuestro ambiente". Más concretamente, se creía estar viviendo "una etapa decisiva en nuestra evolución", donde el gobierno de Yrigoyen aparecía como "el corolario lógico". En efecto, el radicalismo expresaba un "sentimiento primario", de oposición "al despotismo que aprisionaba al país hacía más de treinta años". El último cisma que habia vivido el PS, con la salida de los internacionalistas, mostraba que la "casta sacerdotal" que lo gobernaba era ahora "excomulgada por los feligreses”, aún más doctrinarios que el grupo dirigente -el PS-A juzgaba esa "extrema izquierda" sincera pero ingenua-. Reivindicaba su ideal de justicia y solidaridad social, en particular su lucha contra el latifundio, implantando un impuesto directo y progresivo contra la renta del suelo, acelerando la transformación del viejo derecho de propiedad. Se reafirmaba, además, el combate contra la explotación del trabajo, la inseguridad del salario, las malas condiciones de higiene en las fábricas y el fomento de la agremiación y del cooperativismo. Asimismo, se atacaban los privilegios del culto católico, se reclamaba la formación de una milicia ciudadana, pidiendo la extensión del sufragio a la mujer, la reforma de los códigos y la protección de las libertades. 


\section{Decadencia electoral y lucha feminista}

En las elecciones legislativas de marzo de 1918, Palacios tampoco resulta electo. Sus 35.277 votos muestran una estabilidad de sus apoyos. Y una vez más, la existencia de su candidatura impide a los socialistas alcanzar la victoria en la Capital: los radicales obtienen las 7 bancas de la mayoría (contra tres para el PS).

Unos meses más tarde el PS-A obtiene al fin una banca, pero en el Concejo deliberante de la Ciudad de Buenos Aires, que será ocupada por J. Mantecón tras las elecciones del 6 de octubre de $1918 .{ }^{13}$ Se trataba de la primera elección por sufragio "universal" (masculino) y directo, con aplicación del sistema de "cociente", que permitirá a los "Argentinos" entrar en el reparto con 2.912 votos, a título de "residuo", sobre más de 140.000 votantes. ${ }^{14}$

La actividad parecía siempre centrada en la agitación electoral, pero su vida interna acusaba cierto dinamismo. Incluso contaba con una agrupación juvenil, con el nombre "Alberto de Diego", en homenaje a una figura cercana al socialismo asesinado en 1913. A principios de 1920, figuraba J.L. Alberti como su Secretario general, y en ese momento aparecen como sus dirigentes más activos C. Filippa, secretario general del Sindicato de bronceros y anexos, junto a nombres como G.V. Fort, C.M. Brian, G. Spika y Garbellini, mientras se mantienen del grupo original Saldías, Miranda Gallino y Antola.

Para entonces, en una conferencia en la Facultad de Derecho, Palacios muestra sus simpatias con la FORA, "poderoso organismo revolucionario de clase" que realiza incluso funciones de gobierno en reemplazo del Estado, y que en ningún caso puede ser reducido a simples agitadores profesionales. Palacios celebra el ejercicio que hace de ese derecho "formidable" que es la huelga, incluso "general", manifestación de la lucha de clases. Defiende el papel de la acción sindical, que señala "el verdadero camino", actuando incluso como contralor del movimiento político, para que no degenere en mero electoralismo. No falta incluso la clave nacional en su defensa: le da un papel particularmente relevante a su acción en el campo y las regiones alejadas del país, incorporando al movimiento

13. Su hermano Antonio es electo concejal por el PS en esos mismos momentos. Un diario nacional evocaba, para rechazarla de plano, una supuesta incompatibilidad entre ambos mandatos, evocada ante la Junta electoral, que llevaría a la renuncia del hermano menor, Juan.

14. La ley preveía que si el reparto a título del cociente (que era de 4.726 sufragios) no cubría todos los cargos, se adjudicaban a las listas de mayor residuo que excediesen la mitad del cociente. Los socialistas, ganadores del escrutinio, habian logrado 47.971 y 10 representantes comunales, y, siempre a título de comparación, el Partido Socialista Internacional (PSI) obtenía 3.258. 
sindical al indio y al criollo; este último, en particular, "guapo y noble", al "adquirir conciencia de clase", constituirá "una fuerza incontenible en las reivindicaciones proletarias" (Palacios, 1920: 23, 33). ${ }^{15}$

Las elecciones nacionales de marzo de 1920 les brindan la posibilidad de proclamar un nuevo "Manifiesto al pueblo", donde defienden, contra la "montonera electoral", el comicio como ejercicio de la democracia. Y subrayan el papel de contralor que podian ejercer las masas desde el llano, como si presintieran que la suerte les seria adversa una vez más... Pero antes reivindicaban "la conquista de una vida mejor, de una patria más grande, y de una humanidad redimida de dolores". Una vez más, el PS-A ponía en el centro de su programa la defensa de las libertades previstas en la Constitución contra las malas leyes. Aunque puntualizaba que la ley no podía ser una simple frase, y declaraba luchar por la igualdad de posibilidades económicas "hasta llegar a transformar la propiedad privada de la tierra y de los medios de producción y de cambio en propiedad colectiva", procurando así "abatir los privilegios de casta o de clases".

Su programa era conocido: terminar con los malos impuestos, amparar la libertad de culto, impulsar la democratización de la justicia y sobre todo la representación proporcional, y promover siempre la legislación social, defendiendo además la participación de los trabajadores en las ganancias, la jornada de 7 horas y el sábado inglés. "Mientras otras agrupaciones discuten hombres y nombres -termina el documento-nosotros agitamos en el pueblo sentimientos generosos y levantadas ideas", asegurando que no se contentaban con la conquista de algunas bancas, sino que buscaban "con su acción y con su práctica", contribuir "a acelerar el progreso mensurable del pueblo y de las instituciones, por medio de la cooperación, del gremio y de la democracia libre y sana, en todas sus manifestaciones".

La carta que Palacios dirige al partido para aceptar la candidatura a dichos comicios da la pauta de la permanencia del ideario que se buscaba encarnar. Allí se definía al PS-A como una fuerza de jóvenes obreros y estudiantes, que veian a la patria "como fuerza de solidaridad y de justicia social, ajena a todo egoísmo". Incluso, el antiguo diputado socialista entendía que la revolución se estaba concretando en ese Nuevo Derecho que él mismo había iniciado. En esa óptica, puntualizaba que el PS-A no creía que el sindicato fuera el único órgano "capaz de preparar la transformación socialista", aunque las grandes federaciones

15. Aunque toma distancia de su defensa de la acción directa -para él el parlamento "sintetiza y consagra la fuerza creadora que surge del sindicato"-, señala que prepara el advenimiento del nuevo derecho. Saluda incluso su acción de profilaxis dentro del movimiento obrero, en medidas extremas como el boicot. 
sindicales "preparan" con su acción el advenimiento del Nuevo Derecho de manera gradual, a la vez que controlan el movimiento político. En todo caso, la acción parlamentaria "sintetiza y consagra la fuerza combativa y creadora que surge del sindicato". El texto era una ocasión para denunciar una vez más al viejo PS "por desconocer las modalidades nativas" e insistir en lo que constituía la originalidad del PS-A en sentido positivo: "vincular el socialismo como doctrina y como acción con el pensamiento de los organizadores de nuestra nacionalidad". El socialismo en Argentina era la "ampliación inteligente" de lo concebido por la Revolución de Mayo, la obra de Rivadavia, cuya enfiteusis aparecía siempre como "una idea clara y definida de justicia social", y la Asociación de Mayo que era socialista para Echeverría.

Pero los comicios del año 1920 ofrecían al PS-A la ocasión de radicalizar el programa socialista en otra dirección: la lucha por los derechos civiles y politicos de la mujer. En efecto, tanto en las elecciones nacionales de marzo, como en las municipales de noviembre, el partido llevará a una mujer como candidata, Alcira Riglos de Berón de Astrada.

Ciertamente, la sensibilidad "feminista" había estado siempre muy presente en el socialismo argentino, y su Programa mínimo, a la par que promovía el sufragio universal sin distinción de sexos, la igualdad, y el divorcio absoluto, desarrollaba con mayor especificidad el tópico en el ámbito laboral. Por supuesto, la visión estaba centrada en la maternidad de la mujer obrera: se propugnaba la prohibición del trabajo femenino de "todas las industrias que hagan peligrar la maternidad, la salud o la moralidad", la interdicción de trabajo 30 días antes y después del alumbramiento, o se reclamaba la existencia de salas cunas anexas a las fábricas. ${ }^{16}$

Pero la decisión de proponer una candidatura femenina intervenía en un contexto particularmente importante de agitación sufragista, ya que se había constituido un "Comité pro-sufragio femenino", encabezado por Alicia Moreau y Elvira Rawson de Dellepiane, que organizaria en dichas elecciones un "ensayo electoral", conformado por 40 mesas oficiosas en casi todas las seccionales capitalinas donde las mujeres podian depositar su voto, para mostrar su capacidad para participar en la lucha política. Al mismo tiempo, el Partido Feminista Nacional presentaba a las elecciones nacionales con sufragio masculino la candidatura de Julieta Lanteri de Renshaw, que desarrollará una activa campaña electoral. Ambos movimientos son seguidos con cierta simpatía

16. El que fuera su órgano había presentado, a partir del $n^{\circ} 14$, una sección femenina, a cargo de Edith Legarra, pero dando lugar a contribuciones de C. Muzilli sobre el trabajo femenino o publicando páginas de Gabriela L. de Coni, fallecida algunos años antes. A veces se proponían simplemente la traducción de textos europeos. 
por los grandes diarios, que publican incluso imágenes antes y después del comicio, donde no podian faltar leyendas del tipo "una encantadora sufragista", aunque La Vanguardia denunciará el desprecio con que los radicales asumen el problema.

Riglos de Berón de Astrada era, por su parte, una militante de la "valiente agrupación" socialista, ${ }^{17}$ como ponía de manifiesto en su discurso de proclamación de candidatura, en el Teatro Nuevo. Alli celebraba el gesto de incorporar directamente una mujer a la vida politica argentina, con lo cual su partido rompia "con la tradición absurda y repudiable", que, como aseguraba con innegables tintes de radicalidad, no era más que "la consagración de un repudiable y eterno egoísmo de los hombres". El gesto buscaba acelerar una "evolución demasiado lenta y casi sin eficacia" del medio social, moral y político argentino. Una vez más, la guerra había sido "la gran reveladora de la capacidad y de los alcances de la mujer", recordando que "un movimiento de redención femenina y de sufragio universal se ha producido en todos los pueblos de la tierra", subrayando el antecedente uruguayo, al que llamaba "gabinete de experimentación sociológica de América". Para la candidata, "no hay razones para establecer que la mujer sea la eterna esclava de los prejuicios de una sociedad que se derrumba, y no sea en cambio la obrera inteligente de una humanidad que se elabora". Y se mostraba convencida de que en la ciudad de Buenos Aires "el movimiento femenino se insinúa con gran arraigo entre la masa popular".

En todo caso, Riglos juzgaba que su candidatura decretaba la incorporación de la mujer a la vida política argentina. En un plano más específico, llamaba a reformar el Código Civil, de acuerdo al proyecto que había presentado Palacios en su hora, para otorgar los derechos civiles a la mujer, permitiendo en particular que la mujer divorciada dispusiera de sus bienes propios, y que la mujer casada pudiese ejercer toda profesión lícita, además de la libre administración de sus bienes. Tampoco debía tener autorización del marido para ser socia de una cooperativa o de una asociación de socorros mutuos o poseer libreta propia en cajas de ahorro. Asimismo, puntualizaba que la mujer que tenía la patria potestad debía poder administrar los bienes de sus hijos. Por cierto, no olvidaba reclamar el derecho a voto para elegir representantes, con el tinte nacional propio del PS-A: "Nuestro país necesita el aporte y la colaboración de todos sus habitantes, sin distinción de sexo, para la formación de nuestra grandeza nacional", asegurando, bajo los aplausos, que todos los seres "que sentimos las angustias y los

17. Ha habido cierta confusión en la historiografia (Barrancos, 2005), con respecto a la agrupación que llevaba a Riglos de Berón de Astrada. Se trata del PS-A y no del partido histórico, cuya lista era encabezada por Justo y Dickmann. 
placeres de esta tierra, forjaremos el presente y el porvenir de nuestra nacionalidad". ${ }^{18}$

Aunque la candidatura de Riglos de Berón de Astrada había recibido el apoyo de otras dirigentes sufragistas, como E. Rawson de Dellepiane así como una carta de J. Lanteri donde expresaba su satisfacción, alcanzará sólo 2.716 sufragios, siendo con todo la segunda candidata más votada del partido $\left(66^{\circ}\right.$ en el orden general). La candidatura feminista de Lanteri había quedado más rezagada $\left(81^{\circ}\right)$ y la postulante socialista argentina la aventajaba por casi 1.500 votos. Cabe subrayar que durante el ensayo electoral, que había reunido casi 3.500 votos, y cuya Junta escrutadora era también femenina, ${ }^{19}$ se había impuesto ampliamente el PS, con 1.912 boletas, seguido de la candidatura feminista de la doctora Lanteri, que había reunido poco más de 600 sufragios, mientras que los radicales se ubicaban sólo en un demorado tercer lugar con 230, superando apenas al PS-A, que obtenía 208.

Si ya en un reportaje previo Palacios admitía que iban al comicio "sin esperanza de éxito" pero "con la seguridad de que en la suma de sus votos está la comprobación de sus progresos en la opinión", ${ }^{20}$ el resultado de las elecciones era una debacle: su líder apenas superaba los 8.700 votos, ubicándose casi en cincuenteava posición entre los candidatos, cada vez más lejos de Juan B. Justo, que alcanzaba casi 55.000 sufragios -el PS obtenía sólo la representación por la minoría, con 7 bancas-.

Palacios no era sólo el candidato más votado de su partido sino que reunía muchos más sufragios que la lista completa del PS-A, que en esta ocasión había sido de 2.275 boletas, una cifra sensiblemente similar a la de los otros candidatos "Argentinos", que alcanzaban individualmente entre 2.700 y 2.300 votos.

En las elecciones municipales de noviembre de 1920, el socialismo argentino correrá igual suerte, sin posibilidad de renovar su frágil logro de dos años antes. El impulso, ya más menguado, no había faltado y el PS-A organizaba incluso un acto en el Luna Park con la presencia de Palacios. Pero la fuerza no obtenía ninguna banca, sumando apenas 2.306 votos sobre los casi 140.000 sufragios, menos de la mitad del PSI -que lograba nuevamente un concejal-, y muy lejos de los radicales y los socialistas, que obtenían 56.848 y 52.082 respectiva-

18. La Razón, 4 de marzo de 1920.

19. La presidía E. Rawson, y eran secretarias A. García Salaverry y E. Sáenz Hayes, y J.R. de Mantecón. Entre las personalidades que se habían hecho presentes para dar su apoyo a la iniciativa estaban Palacios y Del Valle Iberlucea, que eran considerados desde siempre dirigentes cercanos a la causa femenina

20. La Razón, 5 de marzo de 1920. 
mente. ${ }^{21}$ El PS-A había presentado nuevamente a Riglos de Berón de Astrada, en tercera posición de la lista, pero su candidatura, así como la de Lanteri, era esta vez anulada por la Junta electoral, que decidia, en el caso de la candidata feminista, que su boleta no podía estar presente en el cuarto oscuro, mientras que no se computarian los sufragios de la representante socialista. La Unión Feminista Nacional, en cambio, había podido proceder a un nuevo "ensayo electoral".

La imposibilidad de alcanzar la representación política hería de muerte el proyecto reformista del Socialismo argentino. No por nada una de sus últimas apariciones públicas que quedarian registradas en la prensa era para anunciar su decisión de no presentarse a los comicios nacionales de abril de 1922, imputándola a las reglas del escrutinio que impedian la representación proporcional. Y aconsejaba a sus afiliados el voto en blanco.

$$
* * *
$$

En una arenga pronunciada a principios de 1920, Palacios subrayaba que su nuevo partido había vinculado el socialismo con el nacionalismo, "lo cual no era obstáculo para aceptar las fórmulas más avanzadas del nuevo derecho". Resumía así las coordenadas del proyecto político, entre nacionalismo y reformismo práctico.

Si el discurso en torno a lo nacional conformará el elemento identificativo exterior más fuerte, tal vez el segundo aspecto mostrase mayores facetas. En todo caso, dicho reformismo suponía una labor orientada al orden legislativo, lo que explicaba la importancia de la dimensión jurídica en el ideario del PS-A, y asumía un sentido político muy claro: se trataba de una acción que entrañaba beneficios directos para el pueblo, pero siempre mediados por la ley. ${ }^{22}$ Descartada la implicancia en el movimiento social, este propósito suponía al menos ampliar la base electoral de la fuerza, y, al mismo tiempo, competir con un PS ya consolidado en el espacio capitalino. La tarea se revelaría titánica para el grupo de hombres que rodeaban a Palacios, porque suponía también dar vida a una organización alternativa, y el proyecto -sin una base doctrinal renovada y sólida $-^{23}$ se agotará rápidamente.

El espacio capitalino del socialismo oficial parecía para entonces

21. El PS-A había perdido votos en todas las secciones, con excepción de la $17^{\mathrm{a}}$, muy lejos de la mitad del cociente, que era de 744 votos.

22. La corta labor del concejal Mantecón no parecía haber alcanzado mayor relieve, ni siquiera en la diferenciación con el bloque socialista.

23. En un corto reportaje que se le hace para las elecciones de marzo de $1920, \mathrm{~Pa}-$ lacios señala que si fuera electo, su principal preocupación sería la modificación, 
consolidado. Incluso la retórica nacional había ganado en importancia en las filas socialistas a medida que se consolidaba su lugar en el sistema representativo argentino tras la sanción de la ley Sáenz Peña. Otros elementos que podrian haber coadyuvado para forjar una nueva identidad (el acercamiento con la FORA, el feminismo), no serian acompañados por un accionar partidario capaz de competir con un PS ya fuertemente institucionalizado. En ese marco, el nuevo partido podía aparecer como la expresión de un personalismo exacerbado en torno a la figura de Palacios más que una verdadera ruptura programática. Pero aunque no se consolidó como proyecto político alternativo, el PS-A aparecía como uno de los primeros síntomas de los límites que encerraba el accionar reformista del justismo en el sistema político argentino, su incapacidad en transformarse en una fuerza de gobierno, como quedaría al desnudo una vez más hacia finales de la década de 1920, con la ruptura promovida por Antonio De Tomaso.

\section{Bibliografía}

AA.VV. (1915), El Diputado Palacios. Su separación del Partido Socialista, Buenos Aires: Rosso.

Barrancos, Dora (2005), "Socialismo y sufragio femenino. Notas para su historia”, en H. Camarero y C.M. Herrera (ed.), El Partido Socialista en Argentina. Sociedad, politica e ideas a través de un siglo, Buenos Aires: Prometeo.

Dickmann, Enrique (1917), Democracia y socialismo, Buenos Aires: Ponzinibbio.

García Costa, Víctor (1998), Alfredo Palacios, entre el clavel y la espada. Una biografia, Buenos Aires: Planeta.

Herrera, Carlos Miguel (2018), "La construcción de un socialismo argentino en los años 1910, en torno a Alfredo L. Palacios", Estudios Sociales, Santa $\mathrm{Fe}, \mathrm{n}^{\circ} 55$ (en prensa).

Palacios, Alfredo (1920), La F.O.R.A., Buenos Aires: Agencia Sudamericana de Libros.

en un sentido de ampliación, de las leyes que ya había obtenido como diputado ( $L a$ Razón, 5 de marzo de 1920). 